\title{
Validation of the Declared Withdrawal Periods of Antibiotics
}

\author{
Razia Khatun ${ }^{1}$, Abdul Jabbar Howlader ${ }^{2}$, Shamim Ahmed ${ }^{1}$, Nazrul Islam ${ }^{1}$, Khorshed Alam ${ }^{1}$, \\ Shariar Haider ${ }^{3}$, Mohammad Showkat Mahmud ${ }^{1}$, Md. Amirul Hasan ${ }^{1, *}$ \\ ${ }^{1}$ Bangladesh Livestock Research Institute, Savar, Dhaka, Bangladesh \\ ${ }^{2}$ Department of Zoology, Jahangirnagar University, Savar, Dhaka, Bangladesh \\ ${ }^{3}$ Palli Karma Sahayak Foundations (PKSF), Dhaka, Bangladesh
}

Copyright $(\mathrm{O} 2018$ by authors, all rights reserved. Authors agree that this article remains permanently open access under the terms of the Creative Commons Attribution License 4.0 International License

\begin{abstract}
Drug residues in poultry and poultry products are becoming an alarming or burning concern for public health because of improper use of drugs/feed additive, or failure to observe drug withdrawal period, non-existence of restrictive legislation and lack of consumer awareness in the poultry industry. The declared withdrawal periods and safe level/tolerance level of any antibiotics will be stay in same points. The aim of the study was to validate the declared withdrawal periods and to see whether there is any alteration of these declared withdrawal periods that farmers are practicing in in-situ and ex- situ condition in Bangladesh context. For this, a total of 2100 broilers and 2100 eggs were collected from different markets of poultry rich area in seven divisions of Bangladesh. Seven different drugs such as Enrofloxacin, Oxytetracycline, Ciprofloxacin, Sulfonamide, Cloramphenical, Gentamycin, Furazolidone were used as Maximum Residue Limit (MRL). In case of Enrofloxacin, Ciprofloxacin and Sulfonamides residues persist in broiler meat after the declared withdrawal periods, on the other hand Oxytetracycline, Cloramphenical and Gentamycin maintains the withdrawal period as per stated but the Furazolidone disappears for broiler meat before the declared withdrawal periods. It was found that $55 \%$ poultry samples remain above MRL during 1-3 interval period's in the validation of withdrawal period indicates not safe for human health. It can be concluded that lack of observation of withdrawal period might be a common practice given the high level of antibiotics in the poultry farm of Bangladesh.
\end{abstract}

Keywords Validation, Withdrawal Periods, Antibiotics, Poultry and Bangladesh

\section{Introduction}

Poultry products are important protein source tended to birds are reared as broilers for meat and layers for eggs [17]. The contribution of developing countries to world livestock production and consumption is expected to increase considerably, while the opposite is expected in most developed countries [24]. Commercial poultry farming is a growing sector and its journey started practically during 1980 in Bangladesh [11]. Poultry meat has emerged as a good substitute for beef and mutton. Under intensive and free range management veterinary drugs are essential in poultry production. Veterinary drugs are generally used in farm animals for therapeutic and prophylactic purposes and they include a large number of different types of compound which can be administered in the feed or in the drinking water [19]. Animal products are often contaminated with small quantities of antimicrobial drugs that have been administered to the animal through feed or water. Drug residues containing poultry products (meat, egg and milk) consumed by consumers, makes alteration of the ecology of consumers intestinal flora [10]. Moreover, the addition of antibiotics in poultry feed has been banned in Bangladesh since 2010. Most of the farmers might be aware of the regulation on the use of antibiotics in feed. The higher usage of antibiotics for therapeutic and/or prophylactic purposes as observed is similar to the findings of Sirdar et al [9]. Poor environmental sanitation, unhygienic practices, lack of biosecurity and other management inadequacies leading to increased exposure to bacterial pathogens with resultant immuno-suppression may have contributed to the observed dependence of poultry farms on antibiotics for therapeutic and/or prophylactic purposes.

Antibiotics are used by the poultry industry and poultry veterinarians to enhance growth and feed efficiency and reduce disease. Unfortunately, there is a perception among many consumers that having high concentration of drug or hormone residues in our food supply contains causing significant health concerns or problems [7 and 12]. Antibiotic possess a magical ability to prevent or cure 
virtually any infectious disease, without the eventual loss of activity, has led to overuse and misuse in both developed and developing countries[6]. It has now been recognized by the major world health organizations as one of the top health challenges for this modern era. Some of the causes are widely accepted, for example, the use of antibiotics in livestock or poultry feed as growth promoters, overuse and inappropriate use of antibiotics for nonbacterial infections, and inadequate or indiscriminate antibiotic usage in the clinical arena [9]. Recently US FDA revised Veterinary Feed Directive regulations with a view to reduce use of antimicrobials in animals specifically it will make illegal to use any antimicrobial drug medically important to humans for growth or to improve feed efficiency, monitored by veterinarian oversight of these used drugs to treat, control or prevent diseases in animals .In Bangladesh context An Act to regulate the import, export, manufacture, distribution and sale of drugs called the Drugs Act, 1940. extends to the whole of Bangladesh covers all medicines for internal or external use of human beings or animals intended to be used for or in the treatment, mitigation or prevention of diseases in human beings or animals, not being medicines and substances exclusively used or prepared for use in accordance with the ayurvedic, unani, homoeopathic or biochemic system of medicine.

Antimicrobial agents are widely administered in therapeutic treatment of livestock and poultry and constitute to be a common cause of the presence of chemotherapeutic drug residues in the poultry products and by products [3]. Improper dosages/discontinued course of treatment with antibiotics results in the presence of high level of residues of drugs used in animal and poultry treatment origin in the finished poultry products. Several factors leading to the occurrence of antibiotic residues in animal products: which include failure to observe drug withdrawal periods, poor records of treatment, failure to identify treated animals, lack of advice on withdrawal period, off-label use of antibiotics and availability of antibiotics to lay persons as over the counter drugs in the developing countries [1]. These bad practices lead the antibiotic residues into the food chain and play a pivotal role for development antibiotic resistance. This incidence is not only dangerous for birds but also for human $[5,9.21$ and 25]. Drugs given to birds orally or parentally may be found in tissues, particularly when the birds are slaughtered without observance of withdrawal period or when eggs are harvested within the withdrawal period of the drug [4]. This is more likely in instances where the drug is fed continuously over a long period of time, when used at an extra level dose or beyond recommendation [26]. Use of Antibiotic that might result in deposition of residue in meat, milk and eggs must not be permitted in food intended for human consumption. A withholding period must be observed until the residues are negligible or no longer detected. A withdrawal period must be established to safeguard human from exposure of antibiotic added food. They recorded a high tissue concentration of different broad-spectrum antibiotics in marketed poultry [13]. This condition raises a concern that, if our farmers have no idea about the withdrawal period or they do bother to maintain the drug use in appropriate level, and do not follow the prescription of registered veterinarians. Therefore, the current research was undertaken to measure the level of antibiotics in tissues at some said intervals of ex-situ and check random marketed samples in-situ to compare the drug residue level in the said situations. The ultimate goal of this experiment was to validate the declared withdrawal periods and to see whether there is any alteration of these declared withdrawal periods that farmers are practicing in in-situ and ex- situ condition in Bangladesh context.

\section{Materials and Methods}

\section{(a) Control Research for Validation}

\section{Experimental Birds and their Management}

For validation of declared withdrawal periods of seven antibiotics, a control research was conducted for a period of 44 days with 360 broiler chicks were equally divided into 8 groups, so that group consisted of forty five birds having with three replication. Keeping a control group administration of seven antibiotics was used in recommended dosage to a group of broiler for a specific antibiotic before harvest. The chicks were reared in floor system with standard feeding and management. The supplied feed was also tested of such drug residue before fed the birds in experimental period.

\section{Experimental Protocol}

The chicks were arranged according to a $7 \times 15$ factorial experiment (Seven antibiotices; Enrofloxacin, Oxytetracycline, Ciprofloxacin, Sulfonamide, Cloramphenical, Gentamycin, Furazolidone and 15 periods; 1 day, 3 days, 5 days, 7 days, 9 days, 11 days, 13 days, 15 days, 17 days, 19 days, 21 days, 23days, 25days, 27 days, 29 days) in a Completely Randomized Design (CRD). The antibiotics were administrated to the birds as the following scheme at 15 day's on of control research.

\begin{tabular}{|l|l|}
\hline $\mathbf{T}_{1}=$ Enrofloxacin & $\mathbf{T}_{5}=$ Cloramphenical \\
$\mathbf{T}_{2}=$ Oxytetracycline & $\mathbf{T}_{6}=$ Gentamycin \\
$\mathbf{T}_{3}=$ Ciprofloxacin & $\mathbf{T}_{7}=$ Furazolidone \\
$\mathbf{T}_{4}=$ Sulfonamide & $\mathbf{T}_{8}=$ No antibiotic use \\
\hline
\end{tabular}

After drug administration, collection of tissues were made regularly from the treated and non-treated birds at 15 interval periods and levels of antibiotics residue were observed at different periods to validate the declared withdrawal periods of the antibiotics used for poultry and try to build a relationship of residues level between the 
in-situ and the ex-situ conditions.

\section{Collection of Sample}

Before the sample collection, The Ethical committee inspected the bird's health condition and also justified the necessity of birds slaughtering for this research programme.One bird per replication per interval was taken during experimental periods for slaughter. After slaughter and evisceration, the birds were sampled, placed into a clean plastic bag, labeled accordingly and immediately stored in a cool box ready for shipment to the laboratory. Bird's tissue samples were taken to test the level of residue with commercial drug residue detection kits.

\section{(b) Build-up Relationship of Residues Level between the In-situ and the Ex-situ Conditions}

\section{Collection of Samples}

A total of 2100 broilers and 2100 eggs were collected from different markets of poultry rich area in seven Divisions (Barisal, Khulna, Sylhet, Rangpur, Dhaka, Rajshahi and Chittagong) of Bangladesh. Even number (300) of egg and meat samples was collected from each Division. After slaughter and evisceration, the birds was sampled, placed into a clean plastic bag, labeled accordingly and immediately stored in a cool box ready for shipment to the laboratory. These included breast and thigh muscles, liver and kidney of broilers and eggs were taken to test the level of residue with commercial drug residue detection kits.

\section{Tissues Sample Preparation}

Tissues samples were processed in the laboratory according to the instructions of the used ELISA kit. Approximately $50 \mathrm{~g}$ of each tissue sample was homogenized separately with tissue homogenizer after removing fat from tissue sample. About 1.0g homogenate was taken into a $50 \mathrm{ml}$ polystyrene centrifuge tube and $4 \mathrm{ml}$ $70 \%$ methanol solution was added. Then the mixture was shacked for 10minutes with shaker to mix the solution completely and was centrifuged for $5 \mathrm{~min}$ at $20-50^{\circ} \mathrm{C} @$ $4000 \mathrm{rpm}$. Then $5 \mathrm{ml}$ of the supernatant liquid was transferred to a $2 \mathrm{ml}$ polystyrene centrifuge tube, and then added $0.5 \mathrm{ml}$ of Extraction Buffer Solution. $50 \mu \mathrm{l}$ of the prepared solution was used for assay.

Solution preparation: Solution 1: $1 \times$ Sample Extraction Buffer

1 volume of $10 \times$ Sample Extraction Buffer was mixed with 9 volumes of distilled water.

\section{Egg Sample Preparation}

Samples were processed in the laboratory according to the instructions of the used ELISA kit. The inner part (except shell) of the egg was homogenized separately with homogenizer. Approximately $3.0 \mathrm{~g}$ homogenate was taken into a $50 \mathrm{ml}$ polystyrene centrifuge tube and $6 \mathrm{ml}$ of ethyl acetate was added. Then the mixture was shacked for $3 \mathrm{~min}$ with shaker to mix the solution completely and was centrifuged for 5 minutes at $20-50^{\circ} \mathrm{C} @$ 4000rpm. Four ml of the supernatant liquid was transferred to a $2 \mathrm{ml}$ polystyrene centrifuge tube and used a rotary evaporator to dry the sample in a $50-60^{\circ} \mathrm{C}$ water bath under reduced pressure. Then $2 \mathrm{ml}$ of $\mathrm{n}$-hexane was added to dissolve the dried residue. Again $1 \mathrm{ml}$ of Buffer solution was added and mixed completely by vortex machine for 1 minute. This solution was centrifuged for 10 minutes at room temperature@4000rpm.50 $\mu$ l of the prepared lower aqueous layer per well was used for assay.

Solution preparation: Solution 1: 1×Sample Extraction Buffer

1 volume of $10 \times$ Sample Extraction Buffer was mixed with 9 volumes of distilled water.

Elisa test kit protocol: Preparation of $1 \mathrm{x}$ Wash Solution 1 volume of $20 \times$ Sample Extraction Buffer was mixed with 19 volumes of distilled water.

\section{(c) Detection of Antimicrobial Drug Residue with ELISA}

Collected tissue samples were transferred to the laboratory taking necessary safety measures and maintaining cool chain properly. The tissue samples were stored at $-20^{\circ} \mathrm{c}$ and eggs were stored at room temperature until performance of the test. Residue of antimicrobial drug such as Enrofloxacin, Oxytetracycline, Ciprofloxacin, Sulfonamide, Cloramphenical, Gentamycin, Furazolidone was detected in collected samples (egg and meat) by using Enzyme Linked Immunosorbant Assay (ELISA) according to manufacturer's instructions.

\section{Calculation of Concentrations:}

Relative absorbance $(\%)=\frac{\text { Absorbance standard (or sample) }}{\text { Absorbance zero standard }} \times 100$

\section{(d) Statistical Analysis}

All the collected data were tabulated, summarized and processed for analysis. The collected data were set in Completely Randomized Design (CRD). Statistical analysis of the data was carried out by use of one-way analysis of variance (ANOVA).

\section{Results and Discussion}

The withdrawal periods is the time which passes between the last dose given to the animal and the time when the level of residues in the tissues (muscle, liver, kidney, skin/fat) or products (milk, eggs and egg) is lower than or equal to the MRL/safe level. Until the withdrawal 
period has elapsed, the animal or its products are not safe for human health. It is absolutely true that, the declared withdrawal periods and safe level or Maximum Residue Limit (MRL) of any antibiotic will be stay in same point.

\section{(a) Control Research for Validation of Withdrawal Period}

1. Enrofloxacine Residue Level at Different Withdrawal Period

From the control research results indicated that the detectable residue values of Enrofloxacin were 419, 272, $149,112,78,36$ and $12 \mu \mathrm{g} / \mathrm{kg}$ at 1 day, 3 days, 5 days, 7 days, 9days, 11days and 13days interval withdrawal periods respectively. The declared withdrawal periods of Enrofloxacin were 7 days and safe level of that antibiotic were $70 \mu \mathrm{g} / \mathrm{kg}$ respectively. Experimental results indicated that the declared withdrawal periods and safe level of Enrofloxacin did not stay in same points which are shown in Fig-1. It was observed that $112 \mu \mathrm{g} / \mathrm{kg}$ residue levels at declared withdrawal periods but the safe level is $74 \mu \mathrm{g} / \mathrm{kg}$. So the declared withdrawal periods of Enrofloxacin may not be true for Bangladesh condition due to farmers are not aware about the use of antibiotics for poultry rearing. This result was not similar with findings of [8] where they reported that 5 days for withdrawal period of Enrofloxacin was adequate to get the tissues lower than the maximum residue limits of 100,200 and $300 \mu \mathrm{g} \mathrm{kg}^{-1}$ for muscle, liver and kidney respectively.

The mean residue value of Enrofloxacin was $355 \mu \mathrm{g} / \mathrm{kg}$ in marketed poultry which was found in the build-up relationship of residues level between the in-situ and the ex-situ conditions study. This value was obtained at between 1-3 interval periods in validation research programmed. So the maximum Enrofloxacin residue values in marketed poultry have been found after one to three days of drug administration.

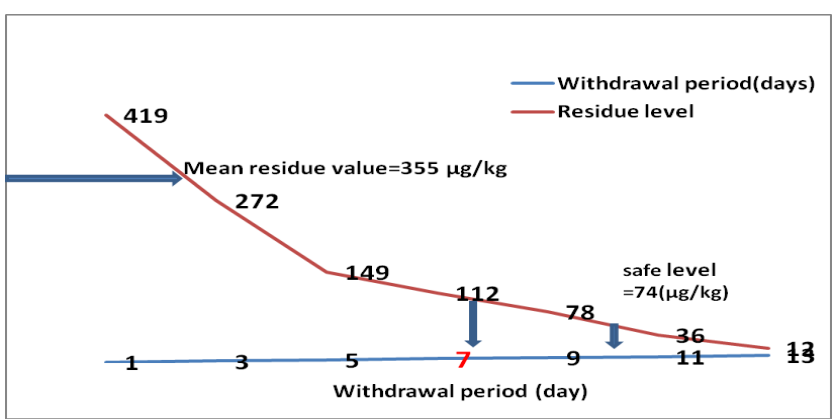

Figure 1. Enrofloxacin residue level $(\mu \mathrm{g} / \mathrm{kg})$ at different withdrawal period

\section{Ciprofloxacin Residue Level at Different Withdrawal Period}

The detectable residue values of Ciprofloxacin were 390, $290,163,70,41$ and $19 \mu \mathrm{g} / \mathrm{kg}$ at 1 day, 3 days, 5 days, 7 days, 9 days and 11 days interval withdrawal periods respectively. The declared withdrawal periods of Ciprofloxacin was 7 days and safe level of that antibiotic was $30 \mu \mathrm{g} / \mathrm{kg}$ respectively. The results indicated that the declared withdrawal periods and safe level of Ciprofloxacin did not stay in same positions which are shown in Fig-2. It was observed that $70 \mu \mathrm{g} / \mathrm{kg}$ residue levels at declared withdrawal periods but the safe level is $30 \mu \mathrm{g} / \mathrm{kg}$. So the declared withdrawal periods of Ciprofloxacin may not be true for our condition. The mean residue value of Ciprofloxacin was $354 \mu \mathrm{g} / \mathrm{kg}$ in marketed poultry which was found in the build-up relationship study. This value was also obtained at 1-3 interval periods in validation research programmed. So the Ciprofloxacin maximum residue values in marketed poultry have been found after one to three days of drug administration due to the random use of ciprofloxacin in the treatment of diseases of commercial layers. Boo et al., [7] also found the similar results.

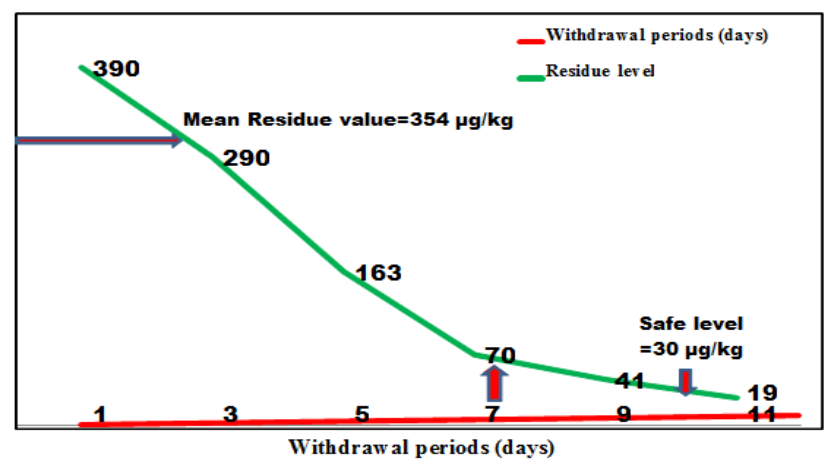

Figure 2. Ciprofloxacin residue level $(\mu \mathrm{g} / \mathrm{kg})$ at different withdrawal period

\section{Sulfonamide Residue Level at Different Withdrawal Period}

The detectable Sulfonamide residue values were 229, 140,54 and $17 \mu \mathrm{g} / \mathrm{kg}$ at 1 day, 3 days, 5 days and 7 days interval withdrawal periods respectively. The declared withdrawal period of Sulfonamide at 4 days were $100 \mu \mathrm{g} / \mathrm{kg}$ respectively. The results indicated that the declared withdrawal periods and safe level of Sulfonamide did not stay in same points which are shown in Figure 3. It was reported that at $240 \mu \mathrm{g} / \mathrm{kg}$ residue levels regarded as declared withdrawal periods but the safe level is $100 \mu \mathrm{g} / \mathrm{kg}$. So the declared withdrawal periods of Sulfonamide may not be true for Bangladesh condition. This result was similar with the findings of [17]. They reported that the withdrawal periods of Sulfonamide were not observed by the farmers in all visited farms within the period of the study. So, maximum Sulfonamide residue values in marketed poultry have been found after one day of drug administration. In order to decrease the potential risk to the consumer's health and to ensure the reduction of sulfonamide residues in edible tissues and eggs in an 
acceptable level, these substances must be administered only in recommended concentrations and their respective withdrawal times must be observed [16].

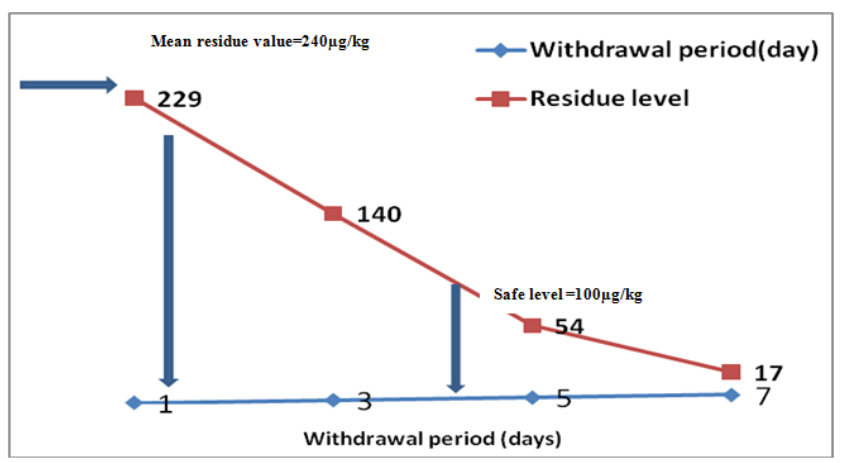

Figure 3. Sulfonamide residue level $(\mu \mathrm{g} / \mathrm{kg})$ at different withdrawal period

\section{Furazolidone Residue Level at Different Withdrawal Period}

The detectable residue values of Furazolidone were 448, 400, 387, 350, 309, 288, 237, 199, 157, 100, 79, 51 and $21 \mu \mathrm{g} / \mathrm{kg}$ at 1 day, 3 days, 5 days, 7 days, 9 days, 11 days, 13 days, 15 days, 17 days, 19 days, 21 days, 23 days and 25 days interval withdrawal periods respectively. The declared withdrawal periods of Furazolidone were 28 days and safe level of that antibiotics were $32 \mu \mathrm{g} / \mathrm{kg}$ respectively. The results indicated that the declared withdrawal periods and safe level of Furazolidone did not stay in same points shown in Fig. 4. It was observed that residue levels are totally absent at the declared withdrawal periods but the safe level is $32 \mu \mathrm{g} / \mathrm{kg}$. Furazolidone residue was disappears before the declared withdrawal periods. So the declared withdrawal periods of Furazolidone may not be true for our condition. The mean residue value of Furazolidone was $381 \mu \mathrm{g} / \mathrm{kg}$ in marketed poultry. This value was also obtained at 1-5 interval periods during research validation programmed. So the maximum Furazolidone residue values in marketed poultry have been found after one to five days of drug administration.

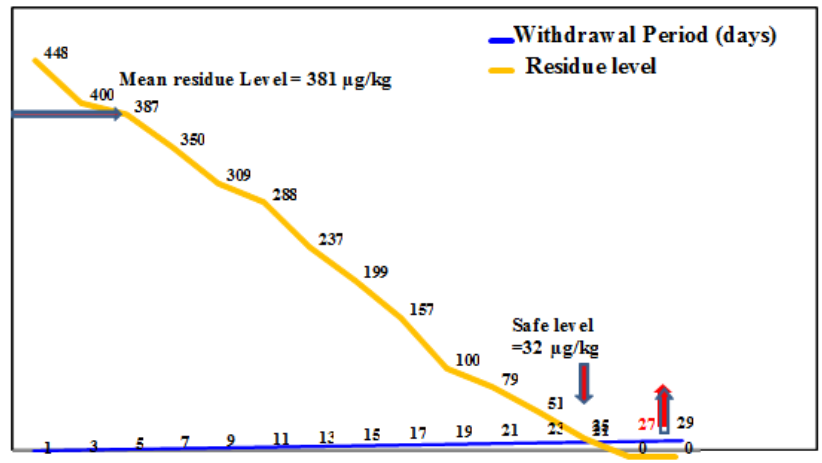

Withdraw al Period (days)

Figure 4. Furazolidone residue level $(\mu \mathrm{g} / \mathrm{kg})$ at different withdrawal period

\section{Oxytetracycline Residue Level at Different Withdrawal Period}

The detectable residue values of Oxytetracycline were $508,387,213,113,101,43$ and $7.5 \mu \mathrm{g} / \mathrm{kg}$ at 1 day, 3 days, 5 days, 7 days, 9 days, 11 days and 13 days interval withdrawal periods respectively. The declared withdrawal periods of Oxytetracycline were 7days and safe level of that antibiotics were $120 \mu \mathrm{g} / \mathrm{kg}$ respectively. The results indicated that the declared withdrawal periods and safe level of Oxytetracycline are almost nearest position which is shown in Figure 5. It was observed that $113 \mu \mathrm{g} / \mathrm{kg}$ residue levels at declared withdrawal periods but the safe level is $120 \mu \mathrm{g} / \mathrm{kg}$. So the declared withdrawal period of Oxytetracycline is true for Bangladesh condition which was not similar with the findings of [17]. They reported that the withdrawal periods of Oxytetracycline were not observed by the farmers in all visited farms within the period of the study. The mean residue value of Oxytetracycline was $320 \mu \mathrm{g} / \mathrm{kg}$ in marketed poultry which was found in the build-up relationship study. This value was also obtained at 1-5 interval periods in validation research programmed. So the maximum Oxytetracycline residue values in marketed poultry have been found after one to five days of drug administration. The present finding is agreed by [4]. It may be due to the use of tetracycline in feed as the growth promoter and treating of layer.

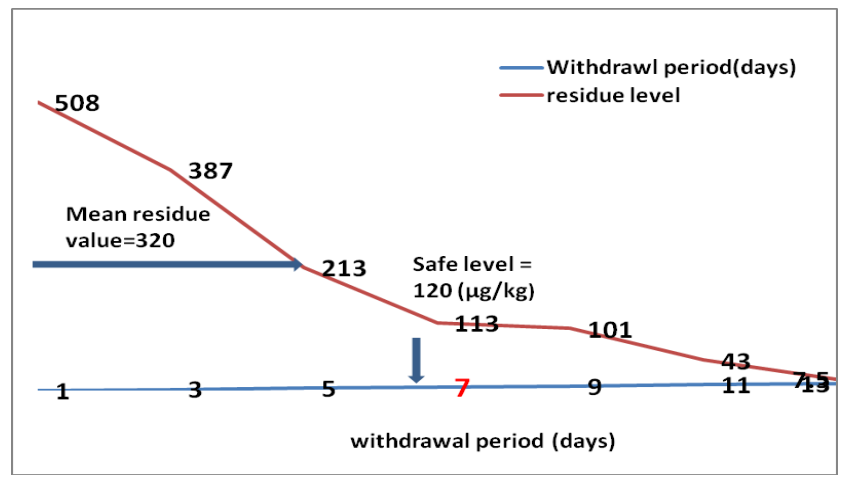

Figure 5. Oxytetracycline residue level $(\mu \mathrm{g} / \mathrm{kg})$ at different withdrawal period

\section{Cloramphenical Residue Level at Different Withdrawal} Period

The detectable residue values of Cloramphenical were $220,199,169,141,127,92,69$ and $37 \mu \mathrm{g} / \mathrm{kg}$ at 1 day, 3 days, 5 days, 7 days, 9 days, 11 days, 13 days and 15days interval withdrawal periods respectively. The declared withdrawal periods of Cloramphenical was 14 days and safe level of that antibiotic was $74 \mu \mathrm{g} / \mathrm{kg}$ respectively. The results indicated that the declared withdrawal periods and safe level of Cloramphenical are almost at close the position which is shown in Figure 6. It was observed that $69 \mu \mathrm{g} / \mathrm{kg}$ residue levels at declared withdrawal periods but the safe level is $74 \mu \mathrm{g} / \mathrm{kg}$. So the declared withdrawal period of Cloramphenical is true for our condition. The mean residue value of Cloramphenical was $255 \mu \mathrm{g} / \mathrm{kg}$ in 
marketed poultry. So the maximum Cloramphenical residue values in marketed poultry have been found after one day of drug administration.

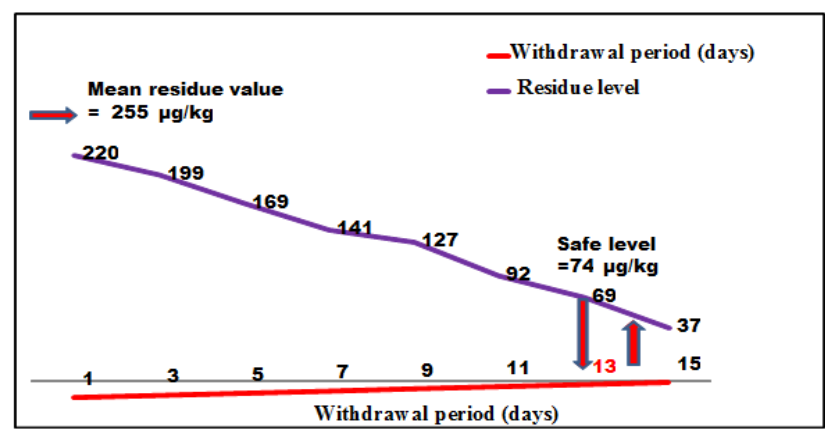

Figure 6. Cloramphenecal residue level $(\mu \mathrm{g} / \mathrm{kg})$ at different withdrawal period

\section{Gentamycin Residue Level at Different Withdrawal} Period

The detectable residue values of Gentamycin were 467, $366,254,188,160,136,110$ and $75 \mu \mathrm{g} / \mathrm{kg}$ at 1 day, 3 days, 5 days, 7 days, 9 days, 11 days, 13 days and 15 days interval withdrawal periods respectively. The declared withdrawal periods of Gentamicin was 14days and safe level of that antibiotics was $100 \mu \mathrm{g} / \mathrm{kg}$ respectively. The results indicated that the declared withdrawal periods and safe level of Gentamycin both were almost in at close position which is shown in Figure 7. It was observed that $110 \mu \mathrm{g} / \mathrm{kg}$ residue levels at declared withdrawal periods but the safe level is $100 \mu \mathrm{g} / \mathrm{kg}$. So the declared withdrawal period of Gentamycin is true for our condition. The mean residue value of Gentamycin was $340 \mu \mathrm{g} / \mathrm{kg}$ in marketed poultry which was found in the build-up relationship study. This value was also obtained at 1-3 interval periods in validation research programmed. So the maximum Gentamycin residue values in marketed poultry have been found after one to three days of drug administration.

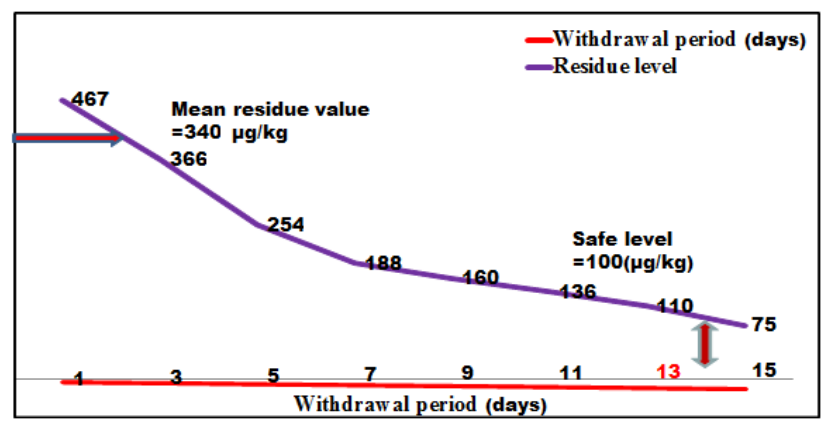

Figure 7. Gentamycin residue level $(\mu \mathrm{g} / \mathrm{kg})$ at different withdrawal period

The result revealed that the declared withdrawal periods of all of those antibiotics may not be true for our condition due to our farmers are not aware about the use of excess level of antibiotics in poultry diet or in the water in the form of powder or liquid causing detrimental effect on human health. They use higher level of antibiotics without knowing the mode of action of that used drugs; they do not maintain withdrawal time, without following registered veterinarians suggestion, or any poultry consultant. This finding relates with [22], he reported that 20 broiler keepers were interviewed to assessment of antimicrobial usage and residues and found $90 \%$ of the respondent admitted to have knowledge on antimicrobial withdrawal period but $95 \%$ did not observe it because of afraid of bird losses but $75 \%$ were not aware about it. The drug residue was completely absent in feed which was given to the birds during the experimental period and also in control group $\left(\mathrm{T}_{8}\right)$. Observed residue level of seven antibiotics at 15 interval periods are shown in Table 1. There was a significant $(p<0.01)$ differences at different interval period. The levels of Ciprofloxacin and Sulfonamides were almost similar to the levels we found in the market samples in the build-up relationship of residues level between the in-situ and the ex-situ conditions study. In case of Enrofloxacin, Ciprofloxacin and Sulfonamide the residues persist after the declared withdrawal periods, Oxytetracycline, Cloramphenical and Gentamycin maintains the withdrawal period stated but the Furazolidone disappears before the declared withdrawal periods.

This finding is supported by Kozarova et al. [18] experiment to determine the residual level of Sulfonamides in poultry meat and eggs, where $43 \%$ meat and $30 \%$ eggs sample had detectable levels of Sulfonamide residues and $23 \%$ meat and $10 \%$ eggs sample contain exceeded recommended maximum residual level resembling not safe for human consumption. This happens due to indiscriminate use of sulfonamide in commercial broiler and layers without observing withdrawal period of this drug. Several types of antimicrobial drugs were reported to be commonly used at farmers level belonging most of tetracycline and sulfonamides [22] group that supported partially with this experiment. It was observed during in-situ and the ex-situ conditions where about $55 \%$ of marketed samples contained above MRL residue level at1-3 interval period's during validation of withdrawal period that was not safe for human health. But it's clear from the result that, antibiotic residue already exist in our food chain, especially in broiler. These findings are in agreement with observation of poultry farms in Nigeria $[2,18]$. Where a high usage of various antibiotics has been reported. However, a comprehensive study require in Bangladesh to detect and estimate all the antibiotics used in broiler and layer chicken to take potential steps to protect the mankind and environment from antibiotics residue hazards. 
Table 1. Antibiotic residue levels at different withdrawal periods after administration of drug

\begin{tabular}{|c|c|c|c|c|c|c|c|c|}
\hline \multirow{2}{*}{$\begin{array}{l}\text { Periods } \\
\text { (Days) }\end{array}$} & \multicolumn{8}{|c|}{ Antibiotics residues $(\mu \mathrm{g} / \mathrm{kg})$} \\
\hline & $\mathrm{T}_{1}$ & $\mathrm{~T}_{2}$ & $\mathrm{~T}_{3}$ & $\mathrm{~T}_{4}$ & $\mathrm{~T}_{5}$ & $\mathrm{~T}_{6}$ & $\mathrm{~T}_{7}$ & $\mathrm{~T}_{8}$ \\
\hline 1 & $419 \pm 8.62$ & $508 \pm 35.31$ & $390 \pm 25.82$ & $229 \pm 22.55$ & $220 \pm 21.21$ & $467 \pm 51.74$ & $448 \pm 25.50$ & - \\
\hline 3 & $272 \pm 8.62$ & $387 \pm 35.26$ & $290 \pm 25.19$ & $140 \pm 56.80$ & $199 \pm 17.45$ & $366 \pm 28.33$ & $400 \pm 22.43$ & - \\
\hline 5 & $149 \pm 8.62$ & $213 \pm 39.02$ & $163 \pm 24.18$ & $54 \pm 28.60$ & $169 \pm 15.98$ & $254 \pm 9.88$ & $387 \pm 17.33$ & - \\
\hline 7 & $112 \pm 8.62$ & $113 \pm 18.93$ & $70 \pm 14.89$ & $17 \pm 31.23$ & $141 \pm 13.83$ & $188 \pm 14.35$ & $350 \pm 17.01$ & - \\
\hline 9 & $78 \pm 8.62$ & $101 \pm 15.53$ & $41 \pm 10.71$ & - & $127 \pm 13.85$ & $160 \pm 12.18$ & $309 \pm 12.20$ & - \\
\hline 11 & $36 \pm 8.62$ & $43 \pm 10.74$ & $19.75 \pm 6.90$ & - & $92 \pm 11.82$ & $136 \pm 8.70$ & $288 \pm 19.53$ & - \\
\hline 13 & $12 \pm 8.62$ & $7.5 \pm 4.15$ & - & - & $69 \pm 13.77$ & $110 \pm 12.27$ & $237 \pm 17.23$ & - \\
\hline 15 & - & - & - & - & $37 \pm 9.88$ & $75 \pm 10.89$ & $199 \pm 13.31$ & - \\
\hline 17 & - & - & - & - & - & - & $157 \pm 9.77$ & - \\
\hline 19 & - & - & - & - & - & - & $100 \pm 7.21$ & - \\
\hline 21 & - & - & - & - & - & - & $79 \pm 11.01$ & - \\
\hline 23 & - & - & - & - & - & - & $51 \pm 8.90$ & - \\
\hline 25 & - & - & - & - & - & - & $21 \pm 7.33$ & - \\
\hline 27 & - & - & - & - & - & - & - & - \\
\hline 29 & & & & & - & - & - & - \\
\hline Sig.level & $* *$ & $* *$ & $* *$ & $* *$ & $* *$ & $* *$ & $* *$ & \\
\hline
\end{tabular}

$* *=$ Significant differences $(\mathrm{p}<0.01)$

$\mathbf{T}_{1}=$ Enrofloxacin, $\mathbf{T}_{2}=$ Oxytetracycline, $\mathbf{T}_{3}=$ Ciprofloxacin, $\mathbf{T}_{4}=$ Sulfonamide, $\mathbf{T}_{5}=$ Cloramphenecal, $\mathbf{T}_{6}=$ Gentamycin, $\mathbf{T}_{7}=$ Furazolidone, $\mathbf{T}_{8}=$ No antibiotic use

Table 2. Detection of drug residue in poultry meat and egg by ELISA method

\begin{tabular}{|c|c|c|c|c|c|c|}
\hline Sample type & Tested sample & Positive & \% Positive & $\begin{array}{c}\text { Positive Sample } \\
\text { (Above MRL) }\end{array}$ & $\begin{array}{c}\text { \% Positive Sample } \\
\text { (Above MRL) }\end{array}$ & Average Sample (Above MRL) \\
\hline Meat & 2100 & 1197 & 57 & 658 & 55 & \multirow{2}{*}{$55 \%$} \\
\hline Egg & 2100 & 777 & 37 & 435 & 56 & \\
\hline
\end{tabular}

(b) Build-up Relationship of Residues Level between In-situ and Ex-situ Conditions

The scenario of drug residue detection in poultry meat and egg by ELISA method is shown in Table 2. Among the total 2100 meat and 2100 examined egg samples were found $1197(57 \%)$ and $777(37 \%)$ positive. A total 658 $(55 \%)$ meat samples and 435(56\%) egg samples were detected with residue levels above [27] standard Maximum Residue Limit (MRL) within the tested positive sample. Average 55\% samples had residue levels above standard Maximum Residue Limit (MRL) during study periods.

\section{(c) Determination of Mean Residue Values of the Seven Antibiotics in Seven Divisions}

The mean sum residue values of the seven antimicrobial drugs in egg and meat shown in Table 3. The higher mean sum residue values in liver was $381 \mu \mathrm{g} / \mathrm{kg}$ for Furazolidone in Rangpur and $355 \mu \mathrm{g} / \mathrm{kg}$ for Enrofloxacinin in Rajshahi Division whereas in egg samples $354 \mu \mathrm{g} / \mathrm{kg}$ Ciprofloxacin in Rajshahi, $340 \mu \mathrm{g} / \mathrm{kg}$ Gentamycin in Dhaka and 277 $\mu \mathrm{g} / \mathrm{kg}$ Sulfonamide in Sylhet division and also in kidney samples, $330 \mu \mathrm{g} / \mathrm{kg}$ Oxytetracyclinein Dhaka and $255 \mu \mathrm{g} / \mathrm{kg}$ Cloramphenical in Chittagong Division. Results of the present experiment showed higher level of residue were present in poultry products supported by [14, 15, 20 and 23] agreement because higher level of antimicrobial agents found in their experimented milk, meat and eggs samples. The mean residue of Furazolidone in liver sample was observed higher than the other mean value of antimicrobial drug. In tissue samples, mean residue in kidney was higher than other organs followed by liver, breast and thigh muscles which were supported by [2]. They mentioned that in different poultry products; liver, breast and thigh muscle samples were tested for the presence of antibiotics residue and liver and breast muscle had found the highest percentage of antibiotic (56\%), followed by for thigh muscle $(44 \%)$. Irrespective of drug residue in all Division and different sample sources Rangpur division found higher than others divisions. 
Table 3. Mean residue values of seven antibiotics in seven divisions

\begin{tabular}{|c|c|c|c|}
\hline Antibiotics & $\begin{array}{c}\text { Mean residue } \\
\text { value }(\boldsymbol{\mu g} / \mathbf{k g})\end{array}$ & Sample type & Division \\
\hline Furazolidone & 381 & Liver & Rangpur \\
\hline Enrofloxacin & 355 & Liver & Rajshahi \\
\hline Ciprofloxacin & 354 & Egg & Rajshahi \\
\hline Gentamicin & 340 & Egg & Dhaka \\
\hline Oxytetracycline & 320 & Kidney & Dhaka \\
\hline Sulfonamide & 240 & Egg & Sylhet \\
\hline Cloramphenecal & 255 & Kidney & $\begin{array}{c}\text { Chittago } \\
\text { ng }\end{array}$ \\
\hline
\end{tabular}

\section{Conclusions}

The declared withdrawal periods of antibiotics residue was found higher than recommended MRL value and this scenario is not only persists not in Bangladesh but also common for the whole world. The results so far revealed that Enrofloxacin, Ciprofloxacin, Sulfonamide Oxytetracycline, Cloramphenical and Gentamycyn after being administered to the broiler, their drug residues level persist in meat on the other hand Furazolidone disappears before the declared withdrawal periods. Different groups of drug having different withdrawal period and their residual action in animal body acts different time. It was observed that $55 \%$ marketed samples remain above MRL residue during detection at 1 to 3 interval of validated declared withdrawal periods indicating badly for human health. This study suggest that widespread misuse of antimicrobial agents by poultry farmers in Bangladesh in different situation (farm level and market condition) resulted lack of implementation of recommended withdrawal times followed by systematic farmer education and regular veterinary supervision. Veterinarians should be promoted to users of an alternative management options like proper vaccinations schedule keeping to reduce the frequency of antimicrobial drug usage in poultry; occurrence of drug residues and spread of drug resistant bacteria. Everyone should be made judicious use of antibiotics in animals to delay the emergence of bacteria resistant. Still, the increased awareness of the scientific community and the stakeholders at the same time were observed. The planning of future strategies is needed towards the solution of this problem. So we have to follow a strict antimicrobial drugs regulation in the poultry industry as well as the inspection of chicken for residues prior to marketing in different poultry and poultry products and also farmers need to be educated on the possible source of excess drug residue level and ensuring the reduction of antimicrobial residues in edible tissues and eggs with acceptable level.

\section{Acknowledgements}

Razia khatun has conducted this experiment and analysis of the collected samples were being done in the laboratory with the assistance of Shamim Ahmed; Md. Amirul Hasan; Md. Khorshed Alam; Md. Shariar Haider has and overall monitor and supervision was accomplished by Professor Abdul Jabber Howlader of his courageous scholastic guidance; continuous assistance, valuable suggestions and constant encouragement throughout the period of this research. Besides these, acknowledge will also goes to Dr. Md. Nazrul Islam, Ex DG (Director General) BLRI (Bangladesh Livestock Research Institute) for arranging facilities and funding in favor of the research work under a research project.

\section{REFERENCES}

[1] Akinynka, Akinwumi, O., Issac, O., Olatoye, Adeyinka, A., Odunsi, Andrew B., Omojola and Tirimisiu, A. (2012). Effects of Antibiotics Residue on the Physical Qualities of Beef in Oyo State, Nigeria. $4^{\text {th }}$ international Conference on Agriculture and Animal Science, 47.

[2] Alo OS, Ojo. Use of antibiotics in food animals; A case of a major veterinary outlet in Ekiti State, Nigeria. Nigerian Veterinary Journal. 2007; 28: 80-2.

[3] Amjad and Habib (2005). Estimation of the Residues of Antibiotics in Poultry Products Available in Local Markets during Summer. J. Chem. Soci., 27:6.

[4] Althaus, R. L., Torres, A., Montero, A., Balasch, S., and Molina, M. P. (2003). Detection limits of antimicrobials in ewe milk by delvotest photometric measurements. J. Dairy Sci., 86:457-463.

[5] Al-Wabel N.A. Monitoring of tetracycline residues in table eggs collected from qassim region, KSA. J. Agric. Vet. Sci. 2011; 4(2):109-123.

[6] Anadon, A., Bringas, P., Martinez-Larranaga, M. R. and Diaz, M. J. (1994). Bioavailability, pharmacokinetics and residues of chloramphenicol in the chicken. Journal of Veterinary Pharmacology and Therapeutics, 17: 52-58.

[7] Bradly, M. S. and Katz, S. E. (1988).Antibiotic/antimicrobials residues in milk. J. Food. Prot. 51: 8-11.

[8] Boo H, Song Y.J, Park S, Chung T.D. Determination of fluoroquinolone antibacterial agents by square weave adsorption stripping voltammetry. J. Korean Electron. Soc. 2010; 13(1):63-69.

[9] Calvin, M., Kunin (1995).Use of Antimicrobial drugs in developing countries. International Journal of Antimicrobial Agents, 5:107-113.

[10] Donoghue, D. J. (2003). Antibiotic Residues in Poultry Tissues and Eggs: Human health concerns. Poultry Sci., $82: 618-621$

[11] Elkholy, H.M., Elkomy, A.A, Awidat, S.K. and Elmajdoub, A. A.(2009).Tissue and Egg Residues and Adverse Effect of Two Oral Enrofloxacin Preparations; Baytril and Enrotryl.Global Veterinaria, 3 (5): 363-368. 
[12] FDA Report (2000).Chemistry and Industry, 22:731.

[13] Haydeee, A. and Mary, B. (2005). Impact of residual and therapeutic doses of ciprofloxacin in the human-floraassociated mice model. Regulatory Toxicology and Pharmacology, 42:151-160.

[14] Haque, Q. M. E. (2001). Poultry industry in Bangladesh and strategies for its improvement. In Proceedings of $2^{\text {nd }}$ International Poultry Show and Seminar, Dhaka, Bangladesh, 34-39.

[15] Hileman, B. (2000). Ibid.78(45):11

[16] Khatun, R., Islam, M. N., Chowdhury, E. H., Rahman, S. M. and Bhuiyan, A. A. (2011).Detection of Ciprofloxacin and Sulfonamide residues in table chicken and egg. Proceeding of Annual Research Review workshop. Bangladesh Livestock Research Institute, 8-9.

[17] Kurwijila, L.R. A., Omore, S., Staal and Mdoe, N.S.Y. (2006). Investigation of the risk of exposure to antimicrobial residues present in marketed milk in Tanzania. J. Food Prot., 69: $2487-2492$

[18] Karimuribo, E.D., Mdegela, R.H., Kusiluka, L.J.M. and Kambarage, D.M. (2005).Assessment of antimicrobial usage and antimicrobial residues in milk on small holder farms in Morogoro Tanzania. Bull. Anim. Health Prod. Afr., 53: 234-241.

[19] Kozarova, I., Mate, D..Hussein, K., Raschmanova, K., Marcincak, S. and Jevinova, P. (2004).High-Performance Liquid Chromatographic Determination of Sulfadimidine Residues in Eggs. Acta Veterinaria, 54(5-6): 427-435.

[20] Kabir, J., Umoh, V. J., Audu-okoh, E., Umoh, J. U. and kwaga, J. K. P.(2004).Veterinary drug use in poultry farms and determination of antimicrobial drug residues in commercial eggs and slaughtered chicken in Kaduma State, Nigeria. Food control, 15:99-105.

[21] Mehtabuddin, A. A. M., Ahmad, T., Nadeem, S., Tanveer, Z. I and Arshad, J. (2012).Sulfonamide residues determination in commercial poultry meat and eggs. The Journal of Animal \& Plant Sciences, 22(2): 473-478 ISSN: 1018-7081.

[22] Milagro, R. and Fidel, T. (2008). Veterinary drug residues in meat: Concerns and rapid methods for detection. Meat Sci., 78:60-67.
[23] Mmbando, L.M.G. (2004).Investigation of oxytetracycline use and abuse determination of its residue in meat consumed in dodoma and Morogoro. MVM. Thesis, MVM Degree at Sokoine University of Agriculture, Morogoro, Tanzania, 240.

[24] Mourot, D. and Loussourorn, S. (1981).Sensibility des ferments lactiques aux antibioticsutilizes an medecine veterinaire. Rec. Med. Vet., 157:175-177.

[25] Nonga, H.E., Mariki, M., Karimuribo, E.D. and Mdegela, R.H. (2009).Assessment of Antimicrobial Usage and Antimicrobial Residues in Broiler Chickens in Morogoro Municipality, Tanzania. Pakistan Journal of Nutrition, 8 (3): 203-207, ISSN 1680-5194

[26] Ogunleye AO, Oyekunle MA, Sonibare AO. Multi-drug resistant Escherichia coli isolates of poultry origin in Abeokuta, South Western Nigeria. Veterinarski Arhiv. 2008; 78: 501-9

[27] Simon, C. (2007).Assessment of antimicrobial usage and antimicrobial residues in layer chickens in Morogoro municipality, Tanzania. A Special Project Report Submitted in Partial Fulfilment for the Degree of Bachelor of Veterinary Medicine of the Sokoine University of Agriculture, Morogoro, Tanzania, 32.

[28] Steinfeld, H. (2004).The livestock revolution -a global veterinary mission. Vet. Parasitol., 125: 19-41.

[29] Samad, M. A. (2003). Bangladesh-A Poultry Shilpey Nirbisarey Antibiotic Baboharer Porinum O Protikar. Poultry Mela, 7: 55-57.

[30] Sirdar MM, Picard J, Bisschop S, Gummow B.A questionnaire survey of poultry layer farmers in Khartoum State, Sudan, to study their antimicrobial awareness and usage patterns. Onderstepoort Journal of Veterinary Research. 2012; 79: 1-8.

[31] Van Dresser, W. R., and Wilcke, J. R. (1989).Drug residues in food animals. Journal of the American Veterinary Medical Association, 194, 1701-1710.

[32] WHO. (1997). The medical impact of the use of antimicrobials in food animals: report of a WHO meeting, Berlin, Germany, Document No. WHO/EMC/ZOO/97.4. 